\title{
Accuracy of Cancer Information on the Internet: A Comparison of a Wiki with a Professionally Maintained Database
}

\author{
M. S. Rajagopalan \\ University of Pittsburgh School of Medicine
}

V. Khanna

Drexel University College of Medicine

M. Stott

Drexel University College of Medicine

Y. Leiter

Bruce and Ruth Rappaport Faculty of Medicine, Technion - Israel Institute of Technology

T. N. Showalter

Thomas Jefferson University and Hospitals.

Follow this and additional works at: hittps://jdc.jefferson.edu/bodinejournal

Part of the Oncology Commons

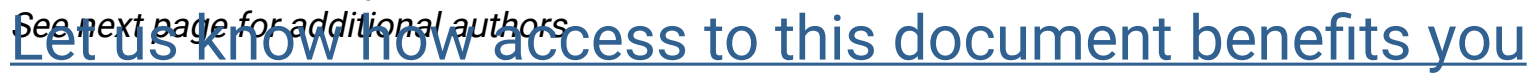

\section{Recommended Citation}

Rajagopalan, M. S.; Khanna, V.; Stott, M.; Leiter, Y.; Showalter, T. N.; Dicker, A.; and Lawrence, Y. L. (2010) "Accuracy of Cancer Information on the Internet: A Comparison of a Wiki with a Professionally Maintained Database," Bodine Journal: Vol. 3 : Iss. 1 , Article 8.

DOI: https://doi.org/10.29046/TBJ.003.1.007

Available at: https://jdc.jefferson.edu/bodinejournal/vol3/iss1/8

This Article is brought to you for free and open access by the Jefferson Digital Commons. The Jefferson Digital Commons is a service of Thomas Jefferson University's Center for Teaching and Learning (CTL). The Commons is a showcase for Jefferson books and journals, peer-reviewed scholarly publications, unique historical collections from the University archives, and teaching tools. The Jefferson Digital Commons allows researchers and interested readers anywhere in the world to learn about and keep up to date with Jefferson scholarship. This article has been accepted for inclusion in Bodine Journal by an authorized administrator of the Jefferson Digital Commons. For more information, please contact: JeffersonDigitalCommons@jefferson.edu. 
Accuracy of Cancer Information on the Internet: A Comparison of a Wiki with a Professionally Maintained Database

\section{Authors}

M. S. Rajagopalan, V. Khanna, M. Stott, Y. Leiter, T. N. Showalter, A. Dicker, and Y. L. Lawrence 


\title{
Accuracy of Cancer Information on the Internet: A Comparison of a Wiki with a Professionally Maintained Database
}

\author{
Rajagopalan, M.S., ${ }^{1}$ Khanna, V., ${ }^{2}$ Stott, M., ${ }^{2}$ Leiter, Y., ${ }^{3}$ Showalter, T.N., ${ }^{4}$ Dicker, A., ${ }^{4}$ Lawrence, Y.L. ${ }^{4}$ \\ ${ }^{1}$ University of Pittsburgh School of Medicine, Pittsburgh, PA \\ ${ }^{2}$ Drexel University College of Medicine, Philadelphia, PA \\ ${ }^{3}$ Bruce and Ruth Rappaport Faculty of Medicine, Technion - Israel Institute of Technology, Haifa, Israel \\ ${ }^{4}$ Department of Radiation Oncology, Thomas Jefferson University and Hospitals, Philadelphia, PA
}

\section{Background}

A Wiki is a website which can be directly, openly edited; Wikipedia, a collaborative encyclopedia, is a well-known example. Due to Wiki's lack of editorial control and formal structure, we hypothesized that the content would be less complete and less accurate than that presented on a formal, peer-reviewed web site. Our goal was to compare the coverage, accuracy, and readability of cancer information from a Wiki (Wikipedia) with a peer-reviewed web site, the patientoriented National Cancer Institute's Physician Data Query (PDQ) comprehensive cancer database.

\section{Methods}

For each of ten cancer types, an appraisal form was created to include content of epidemiology, etiology, symptoms, diagnosis, treatment, and controversial topics in cancer care. Statements were obtained and validated from standard oncology texts. Medically-trained personnel scored PDQ and Wikipedia web pages for accuracy and presentation of controversies. Reliability was assessed using inter-observer variability (correlation coefficient) and test-retest reproducibility (Ebel's algorithm). Readability was calculated from word and sentence length.

\section{Results}

Examiners were able to assess web sites rapidly, with a mean of 18 minutes per article. Test-retest reliability was 0.71 . Inter-observer variability was 0.53 . For both web sites, inaccuracies (as agreed upon by $\geq 2$ raters) were rare and comprised $<2 \%$ of information examined. PDQ was significantly more readable than Wikipedia: Flesch-Kincaid grade level $9.6 \pm 1.5$ vs. $14.1 \pm 0.5(\mathrm{p}<0.0001)$. There was no difference in depth of coverage between PDQ and Wikipedia (29.9 $\pm 8.3,34.2$ \pm 14.0 respectively; max. possible score 72 ). Controversial aspects of cancer care were relatively poorly discussed in both resources (2.9 \pm 2.8 and $6.1 \pm 6.3$ for PDQ and Wikipedia respectively [NS]; max. possible score 18). A planned sub-analysis comparing common to uncommon cancers demonstrated no difference between the two for either resource.

\section{Conclusion}

Although the Wiki resource had similar accuracy and depth to the professionally edited database, it was significantly less readable. Further research is required to assess how this influences patients' understanding and retention. 